\title{
A comparison of the prevalence of IDF- and ATPIII- defined metabolic syndrome in adults aged 50 and over in Ireland: findings from TILDA
}

\author{
D.M. O’Connor, S. Leahy, C.A. McGarrigle and R.A. Kenny \\ The Irish Longitudinal Study on Ageing, Trinity College Dublin, Dublin 2, Ireland
}

Metabolic syndrome (MetS) is described as the clustering of modifiable cardiovascular risk factors including hyperglycaemia, dyslipidaemia, central obesity and hypertension and is a recognised risk factor for type 2 diabetes mellitus (T2DM) and cardiovascular disease $(\mathrm{CVD})^{(1)}$. Those who meet the criteria for MetS have a potential 1.6-fold increase in risk of early mortality ${ }^{(2)}$. In addition, individuals with MetS are more susceptible to many other adverse health conditions, including fatty liver, cholesterol gallstones, asthma, sleep disturbances, and some cancers ${ }^{(3)}$.

This study aimed to determine the national prevalence of MetS in older adults using data from the first wave of The Irish Longitudinal Study on Ageing (TILDA), a nationally representative cohort of community-dwelling adults aged 50 and over. All TILDA participants completed a computer-assisted personal interview (CAPI) and were invited to participate in a comprehensive health assessment. Two sets of criteria were used to calculate prevalence; the Adult Treatment Panel III (ATPIII) ${ }^{(4)}$ and the International Diabetes Foundation (IDF) ${ }^{(5)}$ criteria. Each component of MetS was measured using objective data from the health assessment, i.e. triglycerides, high-density lipoprotein (HDL) cholesterol, blood pressure, waist circumference and glycated haemoglobin $\left(\mathrm{HbA}_{\mathrm{cc}}\right)$, in addition to reported medication usage. Data for each of the five parameters for both the ATPIII and IDF definitions were available for 5026 participants. The prevalence of MetS in the total population and by subgroups of age, sex and educational attainment were generated using the statistical software Stata/MP $12 \cdot 1$.

The mean (SD) age of the sample was 62 (8.5) years; $54.2 \%$ were female. The table shows the prevalence of MetS with $95 \%$ confidence intervals ( $95 \%$ CI) for the older Irish population and subgroups. The ATPIII-defined prevalence of MetS in the population was $41.6 \%$, while the IDF criteria identified $47.3 \%$ as having MetS. For both methods, MetS was more prevalent in men than women and increased with age, with $55 \cdot 3 \%$ [50.3-60.3] and 61.3\% [56.6-66.1] of those aged $\geqslant 75$ years having MetS according to ATPIII and IDF, respectively. The prevalence of MetS decreases with increasing levels of education attainment.

Table. Prevalence of metabolic syndrome in older Irish adults*

\begin{tabular}{llccc}
\hline & \multicolumn{1}{c}{$\begin{array}{c}\text { ATPIII } \\
\text { definition }\end{array}$} & $\begin{array}{c}\text { IDF } \\
\text { definition }\end{array}$ & & \\
\hline Variable & \multicolumn{1}{c}{ Category } & $\mathrm{N}$ & MetS $(\%)[95 \% \mathrm{CI}]$ & MetS $(\%)[95 \% \mathrm{CI}]$ \\
\hline \multirow{3}{*}{ Sex } & & 5026 & $41 \cdot 6[40 \cdot 2-43 \cdot 1]$ & $47 \cdot 3[45 \cdot 8-48 \cdot 8]$ \\
& Male & 2301 & $44 \cdot 2[42 \cdot 2-46 \cdot 2]$ & $51 \cdot 0[49 \cdot 0-53 \cdot 1]$ \\
Age (years) & Female & 2725 & $39 \cdot 1[37 \cdot 2-41 \cdot 1]$ & $43 \cdot 8[41 \cdot 7-45 \cdot 8]$ \\
& $50-64$ & 3215 & $37 \cdot 1[35 \cdot 3-38 \cdot 9]$ & $42 \cdot 8[41 \cdot 0-44 \cdot 7]$ \\
& $65-75$ & 1340 & $49 \cdot 0[46 \cdot 2-51 \cdot 8]$ & $54 \cdot 5[51 \cdot 6-57 \cdot 4]$ \\
Education & $\geqslant 75$ & 471 & $55 \cdot 3[50 \cdot 3-60 \cdot 3]$ & $61 \cdot 3[56 \cdot 6-66 \cdot 1]$ \\
& Primary/none & 1101 & $51 \cdot 4[48 \cdot 5-54 \cdot 4]$ & $55 \cdot 8[52 \cdot 7-58 \cdot 9]$ \\
& Secondary & 2100 & $38 \cdot 2[36 \cdot 0-40 \cdot 4]$ & $44 \cdot 8[42 \cdot 6-47 \cdot 0]$ \\
& Third/higher & 1823 & $37 \cdot 1[34 \cdot 7-39 \cdot 5]$ & $42 \cdot 5[40 \cdot 1-44 \cdot 9]$ \\
\hline
\end{tabular}

ATPIII, Adult Treatment Panel III criteria; IDF, International Diabetes Foundation criteria MetS, metabolic syndrome; $95 \%$ CI, $95 \%$ confidence interval; * prevalence weighted for population $(\geqslant 50$ years) using svy command in STATA

This is the first time that MetS has been estimated at a population level in Ireland. Irrespective of the detection method employed, prevalence of MetS is high amongst the over 50s in Ireland. These results confirm that MetS is a widespread condition and is more prevalent in men, the elderly and those with lower educational attainment. Poor diet and inadequate exercise exascerbate each separate component of MetS criteria, and as a known predictor of T2DM and CVD, MetS further compounds the existing burden on the healthcare system in Ireland. These findings reinforce the public health importance of developing and implementing national screening for MetS and intervention programmes for reducing future ill-health in the older Irish population.

1. Sookoian SPirola Cj (2011) Curr Hypertens Rep 13, 149-57.

2. Harris MF (2013) Aust Fam Physician 42, 524-7.

3. Grundy SM, Brewer HB Jr., Cleeman JI, et al. (2004) Circulation 109, 433-8.

4. Expert Panel on Detection, Evaluation and Treatment of High Blood Cholesterol in Adults (2001) JAMA 285, $2486-97$.

5. International Diabetes Federation (IDF). The IDF consensus worldwide definition of the metabolic syndrome. Available at: http://www.idf.org/ webdata/docs/IDF_Meta_def_final.pdf. Accessed April 1, 2016. 